\title{
New Oral Anticoagulants: An Update
}

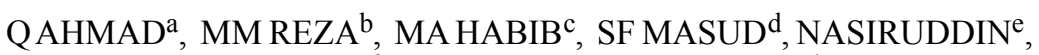 \\ MAKHAN $^{f}$, ASE AMBIYA $^{\mathrm{g}}$, SN AHMAD $^{\mathrm{h}}$
}

\begin{abstract}
Summary:
One of the most common and useful forms of medical intervention is anticoagulant therapy and it is the mainstay of treatment and prevention of thrombosis in different clinical settings, like atrial fibrillation $(A F)$, acute coronary syndrome (ACS), acute venous thromboembolism (VTE), and in patients undergoing invasive cardiac procedures. More than 6 million patients in the United States receive long-term anticoagulation therapy for the prevention of thromboembolism due to AF, placement of a mechanical heart-valve prosthesis, or VTE. ${ }^{1}$ For more than 60 years, until 2009, warfarin and other vitamin $K$ antagonists were the only class of oral anticoagulants (OAC) available.
\end{abstract}

\section{Introduction:}

One of the most common and useful forms of medical intervention is anticoagulant therapy. It is the mainstay of treatment and prevention of thrombosis in different clinical settings, like atrial fibrillation (AF), acute coronary syndrome (ACS), acute venous thromboembolism (VTE), and in patients undergoing invasive cardiac procedures. , $^{2,4,5}$ More than 6 million patients in the United States receive long-term

a. Prof. Quamruddin Ahmad, Prof. \& Head, Department of Neuromedicine, Holy Family Red Crescent Medical College (HFRCMC), Dhaka.

b. Dr. Md Mahin Reza, Resident, Department of Neuromedicine, HFRCMC.

c. Dr. Md. Ahosan Habib, Registrar, Department of Neuromedicine, HFRCMC.

d. Dr. Syed Faravee Masud, Resident, Department of Neuromedicine, HFRCMC.

e. Dr. Nasiruddin, Resident, Department of Neuromedicine, HFRCMC.

f. Dr. Md. Ahsanuzzaman Khan, Resident, Department of Neuromedicine, HFRCMC.

g. Dr. Ahmed Shahed-e-Ambiya, Resident, Department of Medicine, HFRCMC.

h. Dr. Sonia Nasreen Ahmad, Assistant Professor, Department of Medicine, Holy Family Red Crescent Medical College, Dhaka.

Address of Correspondence: Prof. Quamruddin Ahmad, Prof. \& Head, Department of Neuromedicine, Holy Family Red Crescent Medical College (HFRCMC), Dhaka.

Received: 9 August, 2018

Accepted: 29 January, 2019
Although these drugs are highly effective in prevention of $T E$, their use is limited by a narrow therapeutic index that necessitates frequent monitoring and dose adjustments. This results in substantial risk and inconvenience, leading to inadequate anticoagulant prophylaxis. Recently some new $O A C$ have been marketed which are effective, easier to use and has less side effects. Dabigatran is a new oral thrombin inhibitor and Rivaroxaban, Apixaban and Edoxaban are oral factor Xa inhibitors. This review outlines why these new $O A C s$ were essential and describes in detail about these new drugs.

(J Bangladesh Coll Phys Surg 2019; 37: 135-150)

DOI: https://doi.org/10.3329/jbcps.v37i3.41736

anticoagulation therapy for the prevention of TE due to AF, placement of a mechanical heart-valve prosthesis,or VTE. 6 Omission of appropriate anticoagulant prophylaxis is a widely recognized medical error. ${ }^{7}$ Bleeding is the primary complication of anticoagulant therapy, and is a risk of all anticoagulants, ${ }^{8}$ even when maintained within usual therapeutic ranges.

For more than 60 years, until 2009, warfarin and other vitamin $\mathrm{K}$ antagonists were the only class of oral anticoagulants (OAC) available. Although these drugs are highly effective in prevention of thromboembolism, their use is limited by a narrow therapeutic index that necessitates frequent monitoring and dose adjustments resulting in substantial risk and inconvenience. The therapeutic range of anticoagulation for Warfarin is measured via the international normalized ratio (INR). The range is normally 2.0 to 3.0 for $\mathrm{AF},{ }^{9}$ and an INR < 2.0 increases the risk of thromboembolism. ${ }^{10,11}$ An INR $>4.0$ increases the risk of major bleeding, ${ }^{12,13}$ though some studies have shown increased risk of hemorrhage with an INR $>3.0$ also. ${ }^{14}$ This limitation has translated into poor patient adherence and probably contributes to the systematic underuse of vitamin $\mathrm{K}$ antagonists for stroke prevention. ${ }^{15,16}$ Owing to the high-risk profile of warfarin and difficulty of management, only approximately half of those patients with nonvalvular atrial fibrillation who should be 
anticoagulated are anticoagulated. ${ }^{17}$ To compound this under treatment, of those patients' eligible and anticoagulated with warfarin, analysis shows that such patients are only in the therapeutic range approximately $50 \%$ of the time. Keeping the INR in the therapeutic range is difficult due to its variable pharmacodynamics and interactions with other medications and diet and other factors. The percent of time that the INR is within the therapeutic range predicts the risk of adverse events, and in order to obtain maximum benefit, patients must have a minimum threshold of time in the therapeutic range of at least $60 \% .{ }^{18}$ Time in therapeutic range is $60 \%$ to $65 \%$ in controlled clinical trials but may be lower in the true population. ${ }^{19}$ Indeed, time in therapeutic range d" $40 \%$ may completely offset the benefit of vitamin $\mathrm{K}$ antagonists.

\section{Atrial Fibrillation}

Atrial fibrillation (AF) is the most common cardiac arrhythmia responsible for one third of the hospitalizations because of cardiac rhythm disturbances. There is a $25 \%$ lifetime risk in adults for the occurrence of $\mathrm{AF}^{20}$ with rising prevalence and incidence with age, ${ }^{21}$ and future increases predicted. ${ }^{22,23} \mathrm{AF}$ increases the risk of ischemic stroke 5 -fold and accounts for $15 \%$ of stroke, with a $23.5 \%$ attributable risk of stroke at age $80-89$ years,${ }^{24}$ rising with age. ${ }^{25}$ Numbers of AF-related ischaemic strokes at age e" 80 years are projected to triple by 2050 , along with numbers of systemic emboli, unless rates of anticoagulation in older patients increase. ${ }^{26}$

The main focus of managing $\mathrm{AF}$ is on alleviating symptoms, by either rate control or rhythm control. The other focus is on preventing stroke - a devastating outcome - with anticoagulation therapy. The increased stroke risk with $\mathrm{AF}$ is heterogeneous and dependent on cumulative risk of various risk factors. ${ }^{27}$ Table I shows the traditional stroke risk scores which stratify patients into low, moderate, and high-risk groups, although the risk of stroke is a continuum and such an artificial categorization is only of modest predictive value for thromboembolism. In older guidelines, OAC is recommended for high-risk patients, whereas OAC or aspirin is recommended for moderate-risk patients and aspirin is recommended for low-risk patients. ${ }^{28} \mathrm{OACs}$ increase the risk of bleeding manifestations so risk factors for bleeding should be assessed before initiation of OAC therapy. ${ }^{29}$ The HASBLED score (Table II) is a simple score which predicts the risk of bleeding. It incorporates risk factors which are present in community patients and improves predictive value among Warfarin naïve patients. ${ }^{30} \mathrm{~A}$ large Danish study ${ }^{31}$ proved the effectiveness of this score and the HAS-BLED score has been incorporated into international guidelines. ${ }^{32}$ The details of the $\mathrm{CHADS}_{2}$ score and $\mathrm{CHA}_{2} \mathrm{DS}_{2}$-VASc score and the HAS-BLED score is provided in Table II. The most commonly used $\mathrm{CHADS}_{2}$ score has only modest predictive value for stroke and many common stroke risk factors are excluded. ${ }^{33,34}$ The novel $\mathrm{CHA}_{2} \mathrm{DS}_{2}$ VASc score is consistently better at identifying "truly low-risk" subjects, performs at least as well as the CHADS $_{2}$ score $^{35,36}$ (or possibly better ${ }^{37,38}$ ) when predicting "high-risk" subjects, and is included in recent European guidelines. ${ }^{39}$ One recent analysis examining the net clinical benefit (risk of ischemic stroke versus intracranial hemorrhage) found a nonnegative (i.e., neutral or positive) net clinical benefit with OAC in patients with a $\mathrm{CHADS}_{2}$ score of e" 0 and $\mathrm{CHA}_{2} \mathrm{DS}_{2}$-VASc score of $\geq 1$ and a negative net clinical benefit only with a $\mathrm{CHA}_{2} \mathrm{DS}_{2}$-VASc score $=0$ (given the "truly low risk" for these patients). ${ }^{40}$ Of interest, the net clinical benefit was even greater at HAS-BLED scores of $\geq 3$, given that higher risk individuals would have a much greater absolute reduction in stroke risk with warfarin, which would outweigh the small absolute increase in major bleeding events.

Table-I

\begin{tabular}{lcl}
\multicolumn{1}{c}{ Approach to Thromboprophylaxis } & in Patients & with Atrial Fibrillation \\
Risk Category & $\mathrm{CHA}_{2} \mathrm{DS}_{2}$-VASc Score & Recommended \\
\hline $\begin{array}{l}\text { One "major" or } \geq 2 \text { "clinically relevant } \\
\text { nonmajor" risk factors }\end{array}$ & $\geq 2$ & $\begin{array}{l}\text { OAC, given as well-controlled VKA } \\
\text { (INR 2.0 - 3.0) or Dabigatran }\end{array}$ \\
$\begin{array}{l}\text { One "clinically relevant nonmajor" } \\
\text { risk factor }\end{array}$ & 1 & $\begin{array}{l}\text { OAC or Aspirin } 75-325 \mathrm{mg} \text { daily; } \\
\text { preferred: OAC }\end{array}$ \\
No risk factors & 0 & $\begin{array}{l}\text { Either Aspirin } 75-325 \text { mg daily or } \\
\text { No antithrombotic therapy; } \\
\text { Preferred: no antithrombotic therapy }\end{array}$ \\
\hline
\end{tabular}


OAC such as a Vitamin K Antagonist (VKA) adjusted to an intensity range of INR of 2. - 3.0 (target 2.5) in patients with 1 "clinically relevant nonmajor" stroke risk factor (i.e. $\mathrm{CHA}_{2} \mathrm{DS}_{2}$-VASc score =1), Dabigatran at $110 \mathrm{mg}$ twice a day may be considered in view of a similar efficacy with VKA in the prevention of stroke and systemic embolism but lower rates of intracranial hemorrhage and major bleeding compared with the VKA and (probably) aspirin.

$\mathrm{AF}$ indicates arterial fibrillation $\mathrm{CHA}_{2} \mathrm{DS}_{2}$-VASc, cardiac failure, hypertension, age $75 \mathrm{y}$ (doubled), diabetes, stroke (doubled) - vascular disease, age 65 $74 \mathrm{y}$, and sex category (female) INR, international normalized ratio, $\mathrm{OAC}$, oral anticoagulation such as a vitamin $\mathrm{K}$ antagonist (VKA) adjusted to an intensity range of INR of $2.0-3.0$ (target 2.5).

*Adapted from European Society of Cardiology 2010 guidelines. The guidelines clearly state that antithrombotic therapy is necessary in patients with $\mathrm{AF}$, unless they are age $<65$ and truly low risk, and thus, female AF patients $\left(\right.$ a $\mathrm{CHA}_{2} \mathrm{DS}_{2}$-VASc score $=$ 1) would not need anticoagulation, if they fulfil the criteria of "age $<65$ and lone AF".

Dabigatran at $150 \mathrm{mg}$ twice a day if a patient is at low risk of bleeding (eg, HAS-BLED score of 0-2) or Dabigatran at $110 \mathrm{mg}$ twice a day considered if a patient has a measurable risk of bleeding (eg, HAS-BLED score of $\geq 3$ )

\section{Table-II}

The $\mathrm{CHADS}_{2}, \mathrm{CHA}_{2} \mathrm{DS}_{2}-\mathrm{VASc}$, and HAS - BLED Scores for Assessing Stroke and Bleeding Risk*

\begin{tabular}{|c|c|c|}
\hline \multicolumn{2}{|c|}{$\mathrm{CHADS}_{2}$} & \multirow{2}{*}{$\frac{\text { Score }}{1}$} \\
\hline I. & Congestive cardiac failure $\dagger$ & \\
\hline II. & $\begin{array}{l}\text { Hypertension (blood pressure consistently }>140 / 90 \mathrm{~mm} \mathrm{Hg} \\
\text { or treated hypertension on medication) }\end{array}$ & 1 \\
\hline III. & Age $\geq 75 y$ & 1 \\
\hline IV. & Diabetes mellitus & 1 \\
\hline \multirow[t]{2}{*}{$\mathrm{V}$. } & Stroke/transient ischemic attack/thromboembolism & 2 \\
\hline & Maximum score & 6 \\
\hline \multicolumn{3}{|c|}{$\mathrm{CHA}_{2} \mathrm{DS}_{2}-\mathrm{VASc}$} \\
\hline I. & Congestive cardiac failure $\dagger$ & 1 \\
\hline II. & $\begin{array}{l}\text { Hypertension(blood pressure consistently }>140 / 90 \mathrm{~mm} \mathrm{Hg} \text { or treated } \\
\text { hypertension on medication) }\end{array}$ & 1 \\
\hline III. & Age $\geq 75$ y & 2 \\
\hline IV. & Diabetes mellitus & 1 \\
\hline V. & Stroke / transient ischemic attack / thromboembolism & 2 \\
\hline VI. & $\begin{array}{l}\text { Vascular disease (previous myocardial infarction, peripheral arterial disease, } \\
\text { or aortic plaque) }\end{array}$ & 1 \\
\hline VII. & Age $65-74$ y & 1 \\
\hline \multirow[t]{2}{*}{ VIII. } & Sex category (ie, female) & 1 \\
\hline & Maximum score & 9 \\
\hline \multicolumn{3}{|c|}{ HAS-BLED } \\
\hline I. & Hypertension (systolic $\geq 160 \mathrm{mmHg}$ ) & 1 \\
\hline II. & Abnormal renal and liver function (1 point each) & 1 or 2 \\
\hline III. & Stroke & 1 \\
\hline IV. & Bleeding tendency or predisposition & 1 \\
\hline V. & Labile international normalized ratio (if on warfarin) & 1 \\
\hline VI. & Elderly (age $\geq 65$ y) & 1 \\
\hline \multirow[t]{2}{*}{ VII. } & Drugs or alcohol (1 point each) & 1 or 2 \\
\hline & Maximum score & 9 \\
\hline
\end{tabular}

$\mathrm{CHADS}_{2}$ score and risk of stroke and TE: 0 , low risk; 1, moderate risk; $\geq 2$, high risk; $\mathrm{CHA}_{2} \mathrm{DS}_{2}-\mathrm{VASc}$ score and risk of stroke and TE: 0 , low risk; 1 , moderate risk; $\geq 2$, high risk; HAS-BLED score and risk of major bleeding: $0-2$, low risk; 3 , high risk. TE - thromboembolism

*Adapted from European Society of Cardiology guidelines 2010. ${ }^{39}$

$\dagger$ Congestive cardiac failure is moderate to severe systolic left ventricular dysfunction, defined arbitrarily as left ventricular ejection fraction $<40 \%$. 
Oral anticoagulation with vitamin $\mathrm{K}$ antagonists (warfarin, phenprocoumon) is successful in both primary and secondary stroke prevention in patients with atrial fibrillation, yielding a $60-70 \%$ relative reduction in stroke risk compared with placebo, as well as a mortality reduction of $26 \%$. In contrast, antiplatelet therapy results in a stroke reduction of $22 \%$, although when the meta-analysis is confined to aspirin only trials, this reduction was a nonsignificant $19 \%$. Compared with antiplatelet therapy, OAC reduces stroke by $37 \%{ }^{41}$ Acetylsalicylic acid (ASA) reduces the relative risk of stroke by a nonsignificant $19 \%$ compared with placebo, and increased bleeding risk offsets any therapeutic gain from the combination of ASA with clopidogrel.

\section{Antiplatelet therapies}

\section{Aspirin}

Aspirin irreversibly inhibits cyclooxygenase, which, in platelets, prevents the production of the platelet agonist TxA2, ${ }^{42}$ thereby attenuating TxA2-mediated platelet activation. However, because aspirin only blocks the TxA2 pathway, platelet activation and subsequent formation of platelet-rich thrombi/emboli via other pathways may still occur.

\section{P2Y12 ADP receptor antagonists}

P2Y12 ADP receptor antagonists inhibit ADP-induced platelet activation by irreversibly binding to the platelet P2Y12 ADP receptor. ${ }^{43}$ The P2Y12 ADP receptor inhibitors include ticlopidine, clopidogrel, and prasugrel, which are pro-drugs that are converted to active metabolite(s), as well as AZD 6140 and cangrelor, which are active drugs that do not require metabolism and are reversible. Properties of these drugs are provided in Table III. Similar to aspirin, ADP antagonists are limited by their inability to block platelet activation and subsequent thrombosis in response to agonists other than ADP. Thus, the most effective therapy for stroke prevention in AF is OAC. As age increases, stroke risk rises, and absolute benefit of OAC increases, whereas absolute benefit of antiplatelet therapy markedly diminishes. Major bleeding risk increases with age, but to a lesser extent than absolute benefit of OAC on stroke. ${ }^{44}$

\section{Venous Thromboembolism}

Venous thromboembolism (VTE), which includes deep vein thrombosis (DVT) and pulmonary embolism (PE), is also a major cause of morbidity and mortality. In the United States, it is estimated that 2 million people develop DVT each year. DVT progresses to PE in 600,000 of these patients, and the PE is fatal in $200,000 .{ }^{45,46}$ In addition to PE, DVT can lead to debilitating postphlebitic syndrome in up to one-third of patients. ${ }^{47}$

Anticoagulant therapy remains the cornerstone of VTE treatment. Such treatment is usually divided into 2 stages. Rapid initial anticoagulation is given to minimize the risk of thrombus extension and

Table-III

\begin{tabular}{|c|c|c|c|c|c|c|}
\hline \multicolumn{7}{|c|}{ Properties of $P 2 Y_{12} A D P$ receptor antagonists } \\
\hline Agent & Class & Administration & Metabolism & $\begin{array}{c}\text { Time to peak } \\
\text { platelet inhibition }\end{array}$ & Rever-sibility & Half-life \\
\hline Ticlopidine & Thienopyridine & Oral & $\begin{array}{l}\text { CYP450-mediated } \\
\text { conversion of pro-drug }\end{array}$ & 4 days $^{\mathrm{a}}$ & $\begin{array}{l}\text { Irrever- } \\
\text { sible }\end{array}$ & N/A \\
\hline Clopidogrel & Thienopyridine & Oral & $\begin{array}{l}\text { CYP450-mediated } \\
\text { conversion of pro-drug }\end{array}$ & $2-6 \mathrm{hrs}{ }^{\mathrm{b}}$ & $\begin{array}{l}\text { Irrever- } \\
\text { sible }\end{array}$ & N/A \\
\hline Prasugrel & Thienopyridine & Oral & $\begin{array}{l}\text { CYP450-mediated } \\
\text { conversion of pro-drug }\end{array}$ & $1 \mathrm{hrc}$ & $\begin{array}{l}\text { Irrever- } \\
\text { sible }\end{array}$ & N/A \\
\hline Cangrelor & ATP analogue & IV & Not a pro-drug & $30 \mathrm{~min}$ & Rever-sible & $3-5 \min$ \\
\hline Ticabrelor & $\begin{array}{l}\text { Cyclopentytria- } \\
\text { zolopyrimidine }\end{array}$ & Oral & Not a pro-drug & $2 \mathrm{hr}$ & Rever-sible & $12 \mathrm{hr}$ \\
\hline
\end{tabular}

CYP450 - Cytochrome P450

${ }^{\mathrm{a}}$ With $500 \mathrm{mg}$ dose $\quad{ }^{\mathrm{b}}$ With $600 \mathrm{mg}$ loading dose. $\quad{ }^{\mathrm{c}}$ With $60 \mathrm{mg}$ loading dose 
subsequent fatal PE, whereas extended anticoagulation is administered to prevent recurrent VTE, thereby reducing the risk of postphlebitic syndrome. With currently available drugs, immediate anticoagulation can only be effected with parenteral anticoagulants, such as heparin, low-molecular-weight heparin (LMWH), or fondaparinux. Extended therapy usually involves the administration of an oral anticoagulant. Till recently, the only orally available anticoagulants were the vitamin $\mathrm{K}$ antagonists, such as warfarin. Warfarin also is problematic in the setting of VTE. Its slow onset of action necessitates overlap with a parenteral anticoagulant for at least 5 days. ${ }^{48}$ In recent years with emerging evidence, patients with unprovoked VTE now require anticoagulation therapy for at least 6 months after their index event, and possibly longer. ${ }^{49}$

\section{New Oral Anti Coagulants}

Due to the various limitations of the vitamin $\mathrm{K}$ antagonists (Table IV), search has been on to find new oral anticoagulants. Two major classes of novel oral agents have been marketed, with more predictable pharmacodynamics than vitamin $\mathrm{K}$ antagonists. ${ }^{50}$ These are:

a) the direct thrombin inhibitors (eg, dabigatran), and

b) factor Xa inhibitors (eg, apixaban, rivaroxaban and edoxaban).

Direct factor $\mathrm{Xa}$ inhibition may cause more coagulation-specific effects, whereas direct thrombin inhibition may have beneficial effects outside the coagulation cascade.

\section{Direct thrombin inhibitors (DTIs)}

Thrombin occupies a central role in the control of haemostasis making it an obvious target for antithrombotic therapy. In addition to blocking the direct generation of fibrin, thrombin inhibitors also inhibit the amplification of the coagulation cascade by blocking the thrombin mediated activation of factors V, VIII and XI, and inhibit thrombin mediated platelet activation.

\section{Table-IV}

\section{Main limitation of current widely used antithrombotics ${ }^{51}$}

Warfarin risk from overdosing and high rethrombosis risk from underdosing

Slow onset of anticoagulant action

Wide inter-individual dose requirements, in part genetically determined

Metabolism by the cytochrome P450 pathway giving rise to a high risk of interaction with co-medications

Sensitivity to dietary vitamin $\mathrm{K}$ leading to day-to-day variation in anticoagulant effect
Unfractionated Heparin

Lack of effect via the oral route

Poor availability from subcutaneous injections and short circulation halflife: need for administration by intravenous infusion

Wide inter-individual dose requirements, in part determined by binding to acute phase proteins

Essential requirement for monitoring of anticoagulant effect

Risk of heparin-induced thrombocytopenia (HIT), often complicated by thrombosis (heparin-induced thrombocytopenia with thrombosis - HITT)
Low molecular weight heparin

Lack of effect via the oral route

Unclear dose requirements in obese and underweight adults and in infants and children. Lack of a routinely available assay.

Accumulation in renal impairment

Role of HITT lower than with unfractionated heparin, but present 


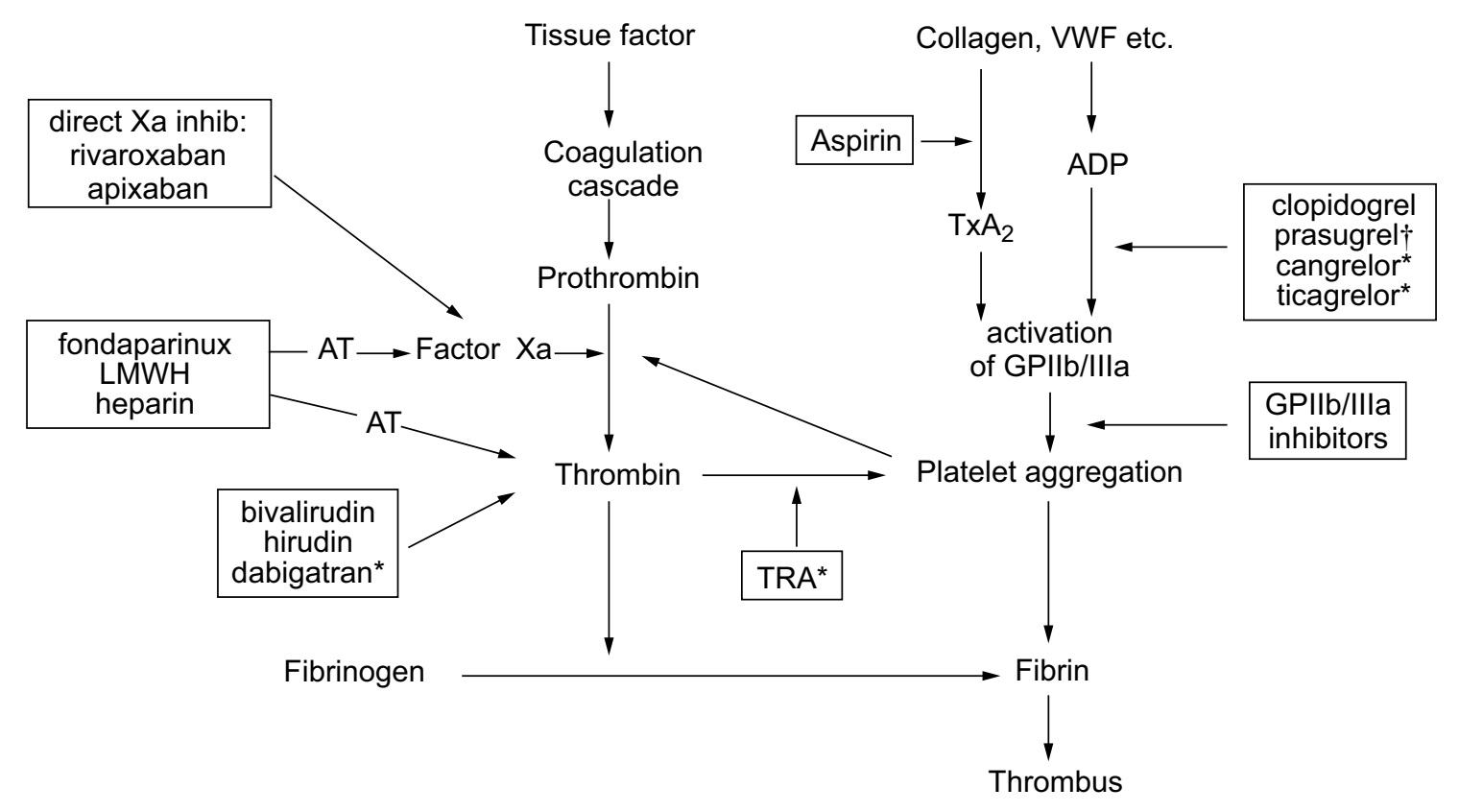

The coagulation cascade, platelet activation pathways, and targets of antithrombotic agents. Simplified presentation of the coagulation cascade and platelet activation pathways together with antithrombotic agents. AT, antithrombin: LMWH, low-molecular-weight heparin; TRA, thrombin receptor antagonist; TA2, thromboxane A2; VWF: Von Willlebrandt factor; *agents recently approved, †recently approved.

Fig.-1: The coagulation cascade and targets of antithrombotic agents

Anticoagulation through inhibition of thrombin is not a novel approach. Unfractionated heparin and to a lesser extent LMWH act by inhibiting thrombin and other activated serine proteases. Heparins achieve this indirectly by binding to and enhancing the activity of the natural anticoagulant antithrombin III. Antithrombin III is a large molecule which cannot permeate fibrin clot. The thrombin inhibitors which directly bind to thrombin, blocking its interactions with its natural substrates are being advocated as the new anticoagulants. Likely advantages of these agents are that they bind to both clot-bound and free thrombin and that unlike heparin they do not bind to neutralising plasma proteins including some acute phase reactants, thus producing more predictable anticoagulation.

Inhibitors of factor Xa block thrombin generation, whereas thrombin inhibitors block the activity of thrombin, the enzyme that catalyzes the conversion of fibrinogen to fibrin. Whether thrombin generation is attenuated or thrombin action is suppressed, the net effect is a reduction in thrombin activity and fibrin formation, events that result in inhibition of coagulation. Limiting thrombin generation or activity is critical because, in addition to its role in fibrin formation, thrombin serves as a potent platelet agonist and amplifies its own generation by feedback activation of factors VIII and V, key cofactors involved in factor $\mathrm{Xa}$ and thrombin generation, respectively.

Two groups of DTIs have emerged. The first includes three products approved by the FDA: argatroban (GlaxoSmithKline), bivalirudin (Angiomax, The Medicines Company), and desirudin (Iprivask, Canyon). They have been developed for intravenous use and have found their main roles in the management of heparininduced thrombocytopenia (HIT) and in percutaneous coronary intervention.

The second, potentially of broader clinical use, includes oral prodrugs that are rapidly biotransformed into their active forms. They are targeted for use as longer-term antithrombotics, especially in venous thromboembolism and atrial fibrillation. The first oral direct thrombin inhibitor to be marketed, ximelagatran, was withdrawn in 2004 due to severe hepatotoxicity. ${ }^{50}$ Dabigatran is now available in the market. 


\section{Dabigatran Etexilate}

Dabigatran etexilate, a prodrug of dabigatran, which reversibly inhibits the active site of thrombin, has an oral bioavailability of $6 \% .{ }^{52}$ After oral administration, dabigatran etexilate

is rapidly and completely converted to dabigatran by esterases. Plasma levels of dabigatran peak 2 hours after drug administration. Dabigatran has a half-life of 14 to 17 hours, which permits once- or twice-daily administration, and $80 \%$ of the drug is excreted unchanged by the kidneys. Dabigatran etexilate is a substrate of the P-glycoprotein (P-gp) transporter. This efflux transporter is highly expressed in the intestine and kidneys, and co-administration of potent

P-gp inhibitors, such as quinidine, can increase plasma levels of dabigatran by reducing its clearance. ${ }^{53}$ Consequently, quinidine is contraindicated in patients taking dabigatran etexilate. Coadministration of dabigatran etexilate and amiodarone, a weak P-gp inhibitor, increases dabigatran levels by $50 \%$ without significantly affecting those of amiodarone. The dosage is $150 \mathrm{mg}$ twice a day, or $75 \mathrm{mg}$ twice a day if renal function is impaired. For a patient who needs surgery that poses a low risk of bleeding, the general recommendation is to stop dabigatran

the night before the surgical procedure. For operations with a greater risk of bleeding, many surgeons recommend stopping the drug 3 or 4 days before. Advantages of dabigatran include that it is not influenced by diet and that the onset of therapeutic benefit is within 1 hour. Although some drugs affect dabigatran, drug interactions are more troublesome with warfarin. A serious concern about dabigatran and the other new agents is that if a bleeding problem arises, the effects of these drugs are not reversible by administration of fresh frozen plasma. Dabigatran is reversible by dialysis; however, if a patient is also hypotensive, dialysis is not an option, and simply waiting for the drug to clear is the only choice.

Another drawback is that therapeutic levels cannot be monitored. If a patient taking warfarin requires cardioversion, the INR is carefully monitored for several weeks beforehand to reduce the risk of stroke. With dabigatran, there is no way to know if a patient is actually taking the drug as prescribed.

\section{Factor Xa Inhibitors}

Factor Xa can be inhibited indirectly through antithrombin or by direct inactivation per se, blocking conversion of prothrombin to thrombin. The oral fXa inhibitors are small molecules that bind reversibly to the active site of fXa. Rivaroxaban, and Apixaban are now available in the market.

\section{Rivaroxaban}

An oxazolidinone derivative with a molecular weight of 436, rivaroxaban is a potent and selective inhibitor of factor Xa. ${ }^{54}$ It binds to the active site of factor Xa and inhibits the enzyme in a reversible and competitive fashion regardless of whether factor $\mathrm{Xa}$ is free in solution or bound within the prothrombinase complex. ${ }^{55}$ Rivaroxaban is well absorbed from the gastrointestinal tract with a bioavailability more than $80 \%$, and food has no major effect on its absorption. Rivaroxaban should be taken with food. Plasma levels of the drug peak in about $3 \mathrm{~h}$. The terminal half-life is 5 to 9 hours in young individuals, and 11 to 13 hours in the elderly. 56

Rivaroxaban has a dual mode of elimination; one third is cleared as unchanged drug via the kidneys, one third is metabolized by the liver via CYP3A4-dependent and -independent pathways with the metabolites then excreted in the feces, and one third is metabolized in the liver with the inactive metabolites then eliminated via the kidneys. Of that found in the urine, $30 \%$ to $40 \%$ reflects unchanged drug that is excreted via a combination of glomerular filtration and tubular secretion, whereas the remainder reflects metabolites. Because of its renal clearance, rivaroxaban must be used with caution in patients with renal insufficiency. Rivaroxaban is a substrate for P-gp, and concomitant administration of potent inhibitors or both P-gp and CYP3A4, such as ketoconazole or ritonavir, is contraindicated because they increase plasma drug levels. Rivaroxaban is metabolized in the liver via CYP 3A4, CYP 2J2, and CYP-independent mechanisms. The drug is contraindicated in patients with severe liver disease because metabolic inactivation may be impaired. Caution must also be exercised in patients receiving treatment with potent inhibitors of both CYP3A4 and P-glycoprotein, such as ketoconazole or ritonavir. Reduced fecal and renal clearance of rivaroxaban by these drugs can cause an exaggerated anticoagulant effect. 
The licensed dose of rivaroxaban is $20 \mathrm{mg}$ once a day. In patients with moderate or severe renal impairment (defined as a creatinine clearance of $15-49 \mathrm{~mL} /$ minute) the recommended dose of rivaroxaban is $15 \mathrm{mg}$ once a day. Rivaroxaban should be taken with food. Like other direct factor Xa inhibitors, rivaroxaban prolongs the prothrombin time (PT) and activated partial thromboplastin time (aPTT), with the PT being more sensitive than the aPTT depending on the reagents used for testing. ${ }^{57}$ However, the effect of the drug on these tests is short-lived, with prolongation only seen at peak drug levels. Factor Xa inhibition is the best test to monitor drug concentrations in plasma.

\section{Apixaban}

An active drug, apixaban is absorbed rapidly, and maximal plasma concentrations are achieved 3 hours after oral administration. The drug is cleared with a terminal half-life of 8 to 14 hours. Apixaban is eliminated via multiple pathways, including hepatic metabolism via CYP3A4 and renal and intestinal excretion. Concomitant treatment with potent inhibitors of CYP3A4 is contraindicated in apixabantreated patients. The licensed dose of apixaban is $5 \mathrm{mg}$ twice daily. A dose of $2.5 \mathrm{mg}$ twice daily is recommended when patients meet at least two of the following criteria: age e 80 years, body weight $\mathrm{d}$ $60 \mathrm{~kg}$, or serum creatinine e $1331 / 4 \mathrm{~mol} / \mathrm{L}(1.5 \mathrm{mg} / \mathrm{dL})$. The lower dose should also be used for patients with severe renal impairment (defined in the Summary of Product Characteristics as a creatinine clearance of $15-29 \mathrm{~mL} /$ minute).

\section{Edoxaban}

Edoxaban is an oral, reversible, direct factor $\mathrm{Xa}$ inhibitor with a linear and predictable pharmacokinetic profile and $62 \%$ oral bioavailability. ${ }^{58}$ It achieves maximum concentrations within 1 to 2 hours, and 50\% is excreted by the kidney. ${ }^{59}$ An active drug that is rapidly absorbed, edoxaban has a half-life of 9 to 11 hours. Edoxaban has a dual mechanism of elimination; approximately one third is eliminated via the kidney, and the remainder is excreted in the feces. The dose of edoxaban is $60 \mathrm{mg}$ once daily, or $30 \mathrm{mg}$ once daily in case of patients with creatinine clearance of 30 to $50 \mathrm{ml}$ per minute or a body weight below $60 \mathrm{~kg}$.

\section{Trials for examining the efficacy of the new drugs:}

In the RE-LY trial, ${ }^{60} 18,113$ patients who had atrial fibrillation and a risk of stroke were randomly assigned in a blinded fashion, to receive fixed doses of dabigatran - $110 \mathrm{mg}$ or $150 \mathrm{mg}$ twice daily — or, in an unblinded fashion, adjusted-dose warfarin. The authors concluded that in patients with atrial fibrillation, dabigatran given at a dose of $110 \mathrm{mg}$ was associated with rates of stroke and systemic embolism that were similar to those associated with warfarin, as well as lower rates of major hemorrhage. Dabigatran administered at a dose of $150 \mathrm{mg}$, as compared with warfarin, was associated with lower rates of stroke and systemic embolism but similar rates of major hemorrhage. An accompanying editorial ${ }^{61}$ also advocated the usefulness of dabigatran, "In summary, although there are qualifications, we can rely on RELY."

The AVERROES trial ${ }^{62}$ was a double blind study in which 5599 patients with atrial fibrillation who were at increased risk for stroke and for whom vitamin $\mathrm{K}$ antagonist therapy was unsuitable, were randomly assigned to receive apixaban (at a dose of $5 \mathrm{mg}$ twice daily) or aspirin (81 to $324 \mathrm{mg}$ per day), to determine whether apixaban was superior. The authors concluded that in patients with atrial fibrillation for whom vitamin $\mathrm{K}$ antagonist therapy was unsuitable, apixaban reduced the risk of stroke or systemic embolism without significantly increasing the risk of major bleeding or intracranial hemorrhage.

In the ROCKET-AF trial, ${ }^{63} 14,264$ patients with nonvalvular atrial fibrillation who were at increased risk for stroke were randomly assigned in a double blind fashion to receive either rivaroxaban (at a daily dose of $20 \mathrm{mg}$ ) or dose-adjusted warfarin. The authors concluded that in patients with atrial fibrillation, rivaroxaban was noninferior to warfarin for the prevention of stroke or systemic embolism. There was no significant between-group difference in the risk of major bleeding, although intracranial and fatal bleeding occurred less frequently in the rivaroxaban group.

In the ARISTOTLE trial, ${ }^{64}$ 18,201 patients with atrial fibrillation and at least one additional risk factor for stroke, were randomly assigned to apixaban (at a dose of $5 \mathrm{mg}$ twice daily) or warfarin (target international normalized ratio, 2.0 to 3.0) in a double-blind fashion. 
The authors concluded that in patients with atrial fibrillation, apixaban was superior to warfarin in preventing stroke or systemic embolism, caused less bleeding, and resulted in lower mortality.

The ENGAGEAF-TIMI $48^{65}$ was a randomized, doubleblind, double-dummy trial comparing two once-daily regimens of edoxaban ( 30 or $60 \mathrm{mg}$ once daily) with warfarin in 21,105 patients with moderate to high-risk atrial fibrillation (median follow-up, 2.8 years). The authors concluded that both once-daily regimens of edoxaban were noninferior to warfarin with respect to the prevention of stroke or systemic embolism and were associated with significantly lower rates of bleeding and death from cardiovascular causes.

The RECOVER ${ }^{66}$ study was a double blind randomized trial in which it was tested whether direct oral thrombin inhibitor dabigatran has a predictable anticoagulant effect and may be an alternative therapy to warfarin for patients who have acute venous thromboembolism. The authors concluded that for the treatment of acute venous thromboembolism, a fixed dose of dabigatran is as effective as warfarin, has a safety profile that is similar to that of warfarin, and does not require laboratory monitoring.

The Hokusai-VTE study ${ }^{67}$ was a randomized, doubleblind, noninferiority study, in which patients with acute venous thromboembolism, who had initially received heparin, received edoxaban at a dose of $60 \mathrm{mg}$ once daily, or $30 \mathrm{mg}$ once daily (e.g., in the case of patients with creatinine clearance of 30 to $50 \mathrm{ml}$ per minute or a body weight below $60 \mathrm{~kg}$ ), or received warfarin. The authors concluded that edoxaban administered once daily after initial treatment with heparin was noninferior to high-quality standard therapy and caused significantly less bleeding in a broad spectrum of patients with venous thromboembolism, including those with severe pulmonary embolism.

The EINSTEIN-PE Investigators trial, ${ }^{68}$ was a randomized, open-label, event-driven, non-inferiority trial involving 4832 patients who had acute symptomatic pulmonary embolism with or without deep-vein thrombosis, in which rivaroxaban $(15 \mathrm{mg}$ twice daily for 3 weeks, followed by $20 \mathrm{mg}$ once daily) was compared with standard therapy with enoxaparin followed by an adjusted-dose vitamin $\mathrm{K}$ antagonist for 3,6 , or 12 months. The authors concluded that a fixed- dose regimen of rivaroxaban alone was noninferior to standard therapy for the initial and long-term treatment of pulmonary embolism and had a potentially improved benefit-risk profile.

\section{Potential drawbacks of new anticoagulants}

The major complication of all anticoagulants is bleeding. When a patient receiving anticoagulant therapy presents with a major bleed, it is desirable to have a safe rapidly-acting antidote to reverse the anticoagulant effects. An antidote also is useful when anticoagulant-treated patients require urgent surgery or suffer from major blunt trauma. The short half-life of these new anticoagulants relative to warfarin is beneficial when discontinuation of anticoagulation is needed. Emergency reversibility, however, is a limitation. Apart from SSR 126517, none of the new agents has a specific antidote. Currently, no medication or transfusion is capable of completely neutralizing or specifically reversing the anticoagulant activity of the direct thrombin or (direct or indirect) factor Xa inhibitors, Thus patients currently using these drugs who suffer from an intracranial haemorrhage are at great risk for continued hemorrhage, hematoma expansion, intraventricular extension, and added morbidity and mortality. In addition to possibly administering oral charcoal to any patient recently ingesting oral anticoagulants, empiric transfusion of plasma coagulation products or recombinant coagulation factors may be considered to neutralize the effects of these new anticoagulants. ${ }^{69}$ Given the more reliable composition of Prothrombin complex concentrates (PCCs), and greater concentration of thrombin and factor X, PCCs may be preferred over Fresh Frozen Plasma (FFP) or recombinant Factor VII a (rF-VIIa). ${ }^{70}$

Since heparinoids, hirudin- like agents and dabigatran possess relatively low or no protein binding, as opposed to other direct or indirect thrombin and factor $\mathrm{Xa}$ inhibitors, hemorrhage in conjunction with these agents may theoretically be more likely to respond to serologic extraction by dialysis. ${ }^{71}$ Although not well studied, dialysis may also clear the direct factor Xa or thrombin inhibitors, all of which are small molecules. Unfortunately, the time required to place central access and administer hemodialysis may prove to be a costly limitation. 
For the new direct thrombin or factor $\mathrm{X}$ inhibitors, research to produce reversing agents is urgently needed given the increasing use of these anticoagulants and the inevitable cerebral and systemic hemorrhages that will ensue.

\section{Contraindications and cautions ${ }^{72}$}

The risk of serious haemorrhage makes certain contraindications applicable to all the new anticoagulants for all indications and doses. These include lesions or conditions considered to be a significant risk factor for major bleeding, e.g. presence of gastrointestinal ulceration; malignant neoplasm at high risk of bleeding; recent brain or spinal injury; recent brain, spinal or ophthalmic surgery; oesophageal varices; arteriovenous malformations; vascular aneurysms or major intraspinal or intracerebral vascular abnormalities. Contraindications also include concomitant treatment with any other anticoagulant agent (e.g. unfractionated heparin, low molecular weight heparin, heparin derivatives, oral anticoagulant). Exceptions are switching of therapy to or from the medicine, or when unfractionated heparin is given at doses necessary to maintain an open central venous or arterial catheter. Special care should be taken when deciding to prescribe these drugs to patients with other conditions, undergoing procedures, or taking concomitant treatments (e.g. non-steroidal antiinflammatory drugs, antiplatelet drugs) which may increase the risk of major bleeding. Annually, 10\% of patients taking antithrombotic agents undergo surgical or other invasive procedures that require temporary discontinuation of therapy. ${ }^{73}$ Pregnancy is a contraindication for rivaroxaban, whereas apixaban use is not recommended during pregnancy. The use of apixaban and rivaroxaban are not recommended in patients receiving concomitant systemic treatment with strong inhibitors of both cytochrome P450 enzyme CYP3A4 and P-glycoprotein (P-gp), such as azoleantimycotics (e.g. itraconazole) or HIV protease inhibitors (e.g. ritonavir). These medicines can more than double the plasma concentration of apixaban and rivaroxaban. In the presence of additional factors that increase drug exposure (e.g. severe renal impairment) this may lead to an increased bleeding risk. The concomitant use of apixaban or rivaroxaban with strong CYP3A4 and P-gp inducers (e.g. rifampicin, phenytoin, carbamazepine, phenobarbital) may lead to an approximately $50 \%$ reduction in apixaban or rivaroxaban exposure and should be co-administered with caution.

\section{Unwanted effects}

In the RE-LY study, ${ }^{60}$ the only unwanted effect that occurred more commonly with dabigatran than with warfarin was dyspepsia (11.3\% with dabigatran $150 \mathrm{mg}$ twice daily vs. $11.8 \%$ with dabigatran $110 \mathrm{mg}$ twice daily vs. $5.8 \%$ with warfarin). More patients discontinued dabigatran than warfarin (around 15\% vs. 10\% with warfarin at 1 year, and around $21 \%$ vs. $17 \%$ at 2 years).

Follow-up of the RE-LY cohort continued for only 2 years, and so information on the long-term safety of dabigatran is limited. The rate of major bleeding was $3.36 \%$ per year in the warfarin group, as compared with $2.71 \%$ per year in the group receiving $110 \mathrm{mg}$ of dabigatran $(\mathrm{P}=0.003)$ and $3.11 \%$ per year in the group receiving $150 \mathrm{mg}$ of dabigatran $(\mathrm{P}=0.31)$. The rate of hemorrhagic stroke was $0.38 \%$ per year in the warfarin group, as compared with $0.12 \%$ per year with $110 \mathrm{mg}$ of dabigatran $(\mathrm{P}<0.001)$ and $0.10 \%$ per year with 150 $\mathrm{mg}$ of dabigatran $(\mathrm{P}<0.001)$. The mortality rate was $4.13 \%$ per year in the warfarin group, as compared with $3.75 \%$ per year with $110 \mathrm{mg}$ of dabigatran $(\mathrm{P}=0.13)$ and $3.64 \%$ per year with $150 \mathrm{mg}$ of dabigatran $(\mathrm{P}=$ $0.051)$.

In the RE-COVER study, ${ }^{66}$ major bleeding episodes occurred in $1.6 \%$ (20) patients assigned to dabigatran and in $1.9 \%$ (24) patients assigned to warfarin, and episodes of any bleeding were observed in 16.1\% (205) patients assigned to dabigatran and $21.9 \%$ (277) patients assigned to warfarin. The numbers of deaths, acute coronary syndromes, and abnormal liver-function tests were similar in the two groups. Adverse events leading to discontinuation of the study drug occurred in $9.0 \%$ of patients assigned to dabigatran and in $6.8 \%$ of patients assigned to warfarin $(\mathrm{P}=0.05)$. There have been two published case reports of serious bleeding associated with dabigatran used at lower doses $(75 \mathrm{mg}$ twice daily and $110 \mathrm{mg}$ twice daily) in women aged 84 and 89 years. ${ }^{74}$

The safety of apixaban has been assessed in 11,886 patients with non-valvular AF in studies for an average of 1.7 years. In ARISTOTLE ${ }^{64}$ and AVERROES, ${ }^{62}$ $35.0 \%$ and $22.2 \%$ of patients taking apixaban experienced serious adverse reactions compared with 
$36.5 \%$ and $27.2 \%$ of warfarin and aspirin patients respectively. Major, minor and clinically relevant nonmajor bleeding events occurred in $11.7 \%$ of apixaban patients compared with $9.9 \%$ of aspirin patients. In ARISTOTLE, $18.1 \%$ of apixaban patients had a bleeding event compared with $25.8 \%$ of warfarin patients $(\mathrm{p}<0.001)$. Common adverse reactions were epistaxis, confusion, haematuria, haematoma, eye haemorrhage (including conjunctival haemorrhage) and gastrointestinal haemorrhage. In ARISTOTLE the annual event rate for gastrointestinal bleeding was $0.76 \%$ with apixaban vs. $0.86 \%$ with warfarin.

In the ROCKET-AF trial, ${ }^{63}$ rates of major and clinically relevant non-major bleeding were similar with rivaroxaban and warfarin $(14.9 \%$ vs. $14.5 \%)$ as were rates of major bleeding ( $3.6 \%$ and $3.4 \%, \mathrm{p}=0.58)$. The annual event rate for gastrointestinal bleeding was $3.2 \%$ with rivaroxaban vs. $2.2 \%$ with warfarin. A metaanalysis of five randomised controlled trials that reviewed the bleeding risk with rivaroxaban showed that compared with warfarin, rivaroxaban was not associated with an increased risk of a composite endpoint of major or clinically relevant non-major bleeding. Rivaroxaban was associated with a significant decrease in fatal bleeding and a decreased risk of intracranial bleeding compared with warfarin but it was not associated with a decreased risk in all-cause mortality. ${ }^{75}$ A rebound effect has been reported when rivaroxaban is discontinued. There is a potential for inadequate anticoagulation during the transition to vitamin $\mathrm{K}$ antagonists (e.g. warfarin).

The safety profile of edoxaban has also been favourable. In the ENGAGE AF- TIMI 48 trial, ${ }^{65}$ the annualized rate of major bleeding events was $3.43 \%$ with warfarin, as compared with $2.75 \%$ with high-dose edoxaban and $1.61 \%$ with low dose edoxaban. The rates of life-threatening bleeding, intracranial bleeding, and major bleeding plus clinically relevant nonmajor bleeding were $0.78 \%$, $0.85 \%$, and $13.02 \%$, respectively, with warfarin, as compared with $0.40 \%, 0.39 \%$, and $11.10 \%$, respectively, with high-dose edoxaban and $0.25 \%$, $0.26 \%$, and $7.97 \%$, respectively, with low-dose edoxaban $(\mathrm{P}<0.001$ for the comparison of warfarin with each dose of edoxaban). The annualized rate of major gastrointestinal bleeding was higher with high-dose edoxaban than with warfarin (1.51\% vs. $1.23 \%)$, but the rate was lowest with low-dose edoxaban $(0.82 \%)$.

Finally, the cost of new anticoagulants will impact on their uptake, particularly if these drugs prove only to be as safe and effective as existing agents. Although regulatory agencies may approve the new agents on the basis of noninferiority compared with warfarin, payers are unlikely to embrace the higher cost of new anticoagulants in the absence of superior efficacy or safety over warfarin. Warfarin may be difficult to administer in an effective fashion, but it is inexpensive, even with the added expense of coagulation monitoring. ${ }^{76}$ Unless the cost of the new anticoagulants is relatively low, these drugs are likely to be reserved for patients who cannot be adequately controlled on warfarin, or for those without ready access to a laboratory.

\section{Meta-analyses $^{72}$}

There are no head to head trials comparing any of the four new oral anticoagulant drugs. Several systematic reviews and meta-analyses have used the trial data from the studies of the individual drugs to make comparisons between them.

Table-V

Drug Dose Annual Treatment Cost ${ }^{72}$

\begin{tabular}{llc}
\multicolumn{2}{c}{ Drug Dose Annual Treatment Cost } \\
Drug & Dose & Annual treatment cost \\
\hline Apxiban & $5 \mathrm{mg}$ or $2.5 \mathrm{mg}$ twice daily & $£ 802$ \\
Dabigatran & $150 \mathrm{mg}$ or $110 \mathrm{mg}$ twice daily & $£ 802$ \\
Rivaroxaban & $20 \mathrm{mg}$ or $15 \mathrm{mg}$ once daily & $£ 767$ \\
Warfarin* & Variable & $£ 45+£ 241$ for INR monitoring \\
\hline
\end{tabular}

Drug costs based on prices in Chemist and Druggist and the Drug Tariff.

*Costs for warfarin based on NICE Technology Appraisal 249 costing template. 
In the evidence submission for the technology appraisal for apixaban, the National Institute for Health and Care Excellence (NICE) reviewed two network analyses undertaken by the company. ${ }^{77}$ The first analysis included data from ARISTOTLE, ROCKET-AF and RELY and the second analysis also included data from AVERROES. However, the results were not sufficiently robust to reliably differentiate between apixaban, rivaroxaban and dabigatran. A network meta-analysis (50,578 patients) of three studies (RE-LY, ROCKETAF and ARISTOTLE) reviewed the composite outcome of ischaemic stroke and systemic embolism, major bleeding, intracerebral bleeding, mortality and myocardial infarction. The authors suggested that apixaban or dabigatran $110 \mathrm{mg}$ twice daily may offer the best benefit-risk balance for stroke prevention and that dabigatran $150 \mathrm{mg}$ twice daily may be preferred for patients at higher risk of embolism. ${ }^{78}$ However, an adjusted indirect meta-analysis $(50,578$ patients) of the same studies concluded that the overall superiority of the newer oral anticoagulants over warfarin is largely influenced by the reduction of haemorrhagic stroke and that dabigatran $150 \mathrm{mg}$ twice daily may have the best risk/benefit profile. ${ }^{79}$ A meta-analysis $(44,733$ patients) and indirect comparison of four trials (PETRO [dabigatran with or without aspirin versus warfarin; 502 patients], RE-LY, ROCKET-AF and ARISTOTLE) concluded that dabigatran lowers the composite of stroke and systemic embolism and ischaemic stroke in comparison to rivaroxaban. ${ }^{80}$ However, the authors only included data for the dose of dabigtran that had been approved by the US Food and Drug Administration. Most analyses showed no difference between the drugs, and no difference between all strokes and mortality was seen. However, the authors concluded that apixaban lowers the risk of major and gastrointestinal bleeding compared with dabigatran and rivaroxaban, and that dabigatran lowers the composite of stroke or systemic emboli, and ischaemic stroke compared with rivaroxaban.

The authors of another systematic review (50,578 patients) concluded that the treatment benefit compared with warfarin was small and varied depending on the level of control achieved with warfarin treatment. ${ }^{81} \mathrm{An}$ analysis of seven studies (52,701 patients) prompted a more optimistic conclusion with the authors recommending that given the superiority of the newer drugs (in terms of efficacy, safety and ease of use) "warfarin should not remain first choice of anticoagulation in patients with non-valvular atrial fibrillation and at least moderate thromboembolic risk". 82 The largest review (21 studies, 80,906 patients) suggested that the three agents are therapeutically comparable when warfarin is inappropriate. ${ }^{83}$ Two other reviews (44,563 patients and 51,895 patients) concluded that the newer agents are more efficacious than warfarin for prevention of stroke and systemic embolism, largely as a result of the reduction in haemorrhagic strokes. ${ }^{84,85}$

The latest meta-analysis pubished in March 2014, ${ }^{86}$ compared new oral anticoagulants with warfarin and included data from the ENGAGE AF-TIMI 48, RE-LY, ROCKET-AF, and ARISTOTLE trials amounting to 42411 participants who received a NOAC and 29272 who received warfarin. The authors concluded that patients receiving high-dose NOACs had fewer stroke and systemic embolic events than patients on warfarin, a result mainly driven by substantial protection against haemorrhagic stroke. The NOACs had an overall favourable safety profile as compared with warfarin, although they were associated with an increase in gastro-intestinal bleeding. A reduced all-cause mortality was observed with NOACs in comparison with warfarin. But an accompanying editorial ${ }^{87}$ commented, "Such a meta-analysis assumes that all the novel oral anticoagulant drugs are the same (which they are not) and work on the basis of a class effect or are broadly equivalent; and that the randomised trials are homogeneous, which again they are not".

\section{Conclusion:}

Warfarin has been the standard for oral anticoagulation for over 50 years. The newer oral anticoagulant agents (apixaban, dabigatran and rivaroxaban) produce predictable anticoagulation and have been shown to result in similar or better mortality and vascular outcomes compared with warfarin. Systematic reviews and meta-analyses have made indirect comparisons but the results have not been sufficiently robust to reliably differentiate between apixaban, dabigatran or rivaroxaban. Dabigatran was the first of the new oral anticoagulants licensed to prevent stroke in patients with non-valvular atrial fibrillation. It was approved by 
Table-VI

\begin{tabular}{|c|c|c|c|}
\hline \multicolumn{4}{|c|}{ Indications and doses for FDA approved oral anticoagulants ${ }^{91}$} \\
\hline & Atrial Fibrillation & VTE Prevention & VTE Treatment \\
\hline Dabigatran & $150 \mathrm{mg}$ bid; $75 \mathrm{mg}$ bid. $^{\mathrm{a}}$ & - & - \\
\hline Rivaroxaban & $20 \mathrm{mg}$ daily; $15 \mathrm{mg}$ daily ${ }^{\mathrm{b}}$ & $10 \mathrm{mg}$ daily,e & $15 \mathrm{mg}$ bid $\mathrm{x} 21$ days, then $20 \mathrm{mg}$ daily \\
\hline Apixaban & $5 \mathrm{mg}$ daily; $2.5 \mathrm{mg}$ daily ${ }^{\mathrm{c}}$ & - & - \\
\hline
\end{tabular}

${ }^{\text {aF }}$ or patients with a $\mathrm{CrCl}$ of 15 to $30 \mathrm{~mL} / \mathrm{min}$ or a $\mathrm{CrCl}$ of 30 to $50 \mathrm{ml} / \mathrm{min}$ and concomitantly receiving a strong P-glycoprotein inhibitor.

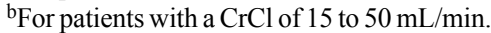

${ }^{\mathrm{c}}$ If the patient is taking a strong dual inhibitor of CYP3A4 and a permeability glycoprotein (P-gp) inhibitor, or has two or more of these characteristics: 80 years of age or older, body weight $60 \mathrm{~kg}$ or less, or serum creatinine $1.5 \mathrm{mg} / \mathrm{dL}$ or greater.

dPostoperative thromboprophylaxis following hip or knee replacement surgery.

${ }^{\mathrm{e}}$ Avoid use in patients with a $\mathrm{CrCl}$ of $30 \mathrm{~mL} / \mathrm{min}$ or lower.

bid=twice daily, $\mathrm{CrCl}=$ creatinine clearance; $\mathrm{CYP}=$ cytochrome $\mathrm{P} 450 ; \mathrm{VTE}=$ venous thromboembolism.

the US Food and Drug Administration in 2010 and by the European Medicines Agency for this use a year later. Once on the market, dabigatran proved a rapid financial success, with global turnover exceeding $\$ 1 \mathrm{bn}$ by April 2012. But, as sales soared, concerns grew about the reports of fatal bleeds that were beginning to emerge. ${ }^{88}$ A QuarterWatch report analysed all the adverse events submitted to the FDA's reporting system in 2011. It found the most commonly identified drugs reported to the FDA were the anticoagulants dabigatran and warfarin. For dabigatran alone, this included 542 patient deaths and 2367 reports of haemorrhage. Warfarin accounted for 72 deaths in the same period. ${ }^{89}$ As of December 2011, the company summary cited 9049 reported bleeding events in its global experience, including 368 deaths. ${ }^{90}$ The company found that if the plasma levels of the drug were measured and the dose was adjusted accordingly major bleeds could be reduced by $30-40 \%$ compared with well controlled warfarin. The adjustment would have little or no effect on the risk of ischaemic stroke. It has also identified the plasma levels at which the dose adjustment should occur to reduce the risk of a major bleed. ${ }^{89}$ Experts are urging that the regulators should recommend plasma level testing of dabigatran in all new patients, and eliminate the recommendation dabigatran "does not in general require routine anticoagulant monitoring." 91

\section{References:}

1. Baron TH, Kamath PS, and McBane RD. Management of Antithrombotic Therapy in Patients Undergoing Invasive Procedures. N Engl J Med 2013;368:2113-124.
2. Buller HR, Agnelli G, Hull RD, et al. Antithrombotic therapy for venous thromboembolic disease: the Seventh ACCP Conference on Antithrombotic and Thrombolytic Therapy. Chest 2004;126:401S-428S.

3. Geerts WH, Pineo GF, Heit JA, et al. Prevention of venous thromboembolism: the Seventh ACCP Conference on Antithrombotic and Thrombolytic Therapy. Chest 2004;126:338S-400S.

4. Braunwald E, Antman EM, Beasley JW, et al. ACC/AHA 2002 guideline update for the management of patients with unstable angina and non- ST-segment elevation myocardial infarctionsummary article: a report of the American College of Cardiology/ American Heart Association task force on practice guidelines (Committee on the Management of Patients With Unstable Angina). J Am Coll Cardiol 2002;40:1366-1374.

5. Antman EM, Anbe DT, Armstrong PW, et al. ACC/AHA guidelines for the management of patients with ST-elevation myocardial infarction: a report of the American College of Cardiology/American Heart Association Task Force on Practice Guidelines (Committee to Revise the 1999 Guidelines for the Management of patients with acute myocardial infarction). J Am Coll Cardiol 2004;44:E1-E211.

6. Roger VL, Go AS, Lloyd-Jones DM, et al. Heart disease and stroke statistics 2012 update. Circulation 2012;125(1):e2-e220.

7. Shojania KG, Duncan BW, McDonald MM, Wachter RM. Making health care safer: a critical analysis of patient safety practices. Evidence Report/Technology Assessment No. 43 (Prepared by the University of California at San FranciscoStanford Evidence-based Practice Center under Contract No. 290-97-0013), AHRQ Publication No. 01-E058, Rockville, MD: Agency for Healthcare Research and Quality. July 2001. http:/ www.ahrq.gov/clinic/ptsafety/.Accessed March 15, 2007.

8. Levine MN, Raskob G, Beyth RJ, Kearon C, Schulman S. Hemorrhagic complications of anticoagulant treatment: the Seventh ACCP Conference on Antithrombotic and Thrombolytic Therapy. Chest 2004;126:287S-310S. 
9. Ansell J, Hirsh J, Poller L, et al. The pharmacology and management of the vitamin K antagonists: the Seventh ACCP Conference on Antithrombotic and Thrombolytic Therapy. Chest 2004;126:204S-233S

10. Hylek EM, Skates SJ, Sheehan MA, Singer DE. An analysis of the lowest effective intensity of prophylactic anticoagulation for patients with nonrheumatic atrial fibrillation. $\mathrm{N}$ Engl J Med 1996;335:540-546.

11. Stroke Prevention in Atrial Fibrillation Investigators. Adjusteddose warfarin versus low-intensity, fixed-dose warfarin plus aspirin for high-risk patients with atrial fibrillation: stroke prevention in atrial fibrillation III randomised clinical trial. Lancet 1996;348:633-38.

12. Anticoagulants in the Secondary Prevention of Events in Coronary Thrombosis (ASPECT) Research Group. Effect of longterm oral anticoagulant treatment on mortality and cardiovascular morbidity after myocardial infarction. Lancet 1994;343:499-503.

13. Mohr JP, Thompson JL, Lazar RM, et al. A comparison of warfarin and aspirin for the prevention of recurrent ischemic stroke. $\mathrm{N}$ Engl J Med 2001;345:1444 -451.

14. Hylek EM, Singer DE. Risk factors for intracranial hemorrhage in outpatients taking warfarin. Ann Intern Med 1994;120: 897-902.

15. Birman-Deych E, Radford MJ, Nilasena DS, Gage BF. Use and effectiveness of warfarin in Medicare beneficiaries with atrial fibrillation. Stroke 2006;37:1070-074.

16. Hylek EM, Evans-Molina C, Shea C, Henault LE, Regan S. Major hemorrhage and tolerability of warfarin in the first year of therapy among elderly patients with atrial fibrillation. Circulation 2007;115:2689-696.

17. Connolly SJ, Eikelboom J, O'Donnell M, Pogue J and Yusuf S. Challenges of establishing new antithrombotic therapies in atrial fibrillation. Circulation 2007;116:449-455.

18. Connolly SJ, Pogue J, Eikelboom J, et al. (2008) Benefit of oral anticoagulant over antiplatelet therapy in atrial fibrillation depends on the quality of international normalized ration control achieved by centers and countries as measured by time in therapeutic range. Circulation 2008;118:2029-037.

19. Garcia-Alamino JM, Ward AM, Alonso-Coello P, et al. Selfmonitoring and self-management of oral anticoagulation. Cochrane Database Syst Rev 2010;4:CD003839.

20. Lloyd-Jones DM, Wang TJ, Leip EP, et al. Lifetime risk for development of atrial fibrillation: the Framingham Heart Study. Circulation 2004;110:1042-046.

21. Heeringa J, van der Kuip DA, Hofman A, et al. Prevalence, incidence and lifetime risk of atrial fibrillation: the Rotterdam Study. Eur Heart J 2006;27:949-953.

22. Miyasaka Y, Barnes ME, Gersh BJ, et al. Secular trends in incidence of atrial fibrillation in Olmsted County, Minnesota, 1980 to 2000, and implications on the projections for future prevalence. Circulation 2006;114:119-125.
23. Singer DE, Albers GW, Dalen JE, et al. Antithrombotic therapy in atrial fibrillation: American College of Chest Physicians Evidence-Based Clinical Practice Guidelines. Chest 2008;133(6 Suppl):546S-592S.

24. Lin HJ, Wolf PA, Kelly-Hayes M, et al. Stroke severity in atrial fibrillation. The Framingham Study. Stroke 1996;27:1760-764.

25. Wolf PA, Abbott RD, Kannel WB. Atrial fibrillation as an independent risk factor for stroke: the Framingham Study. Stroke 1991;22:983-88.

26. Yiin GSC, Howard DPJ, Paul NLM, Mehta Z, Rothwell PM. Incidence, outcome and future projections of atrial fibrillationrelated stroke and systemic embolism at age e" 80 years: 10 year results of a population-based study. J Neurol Neurosurg Psychiatry 2013;84:e2.

27. Hughes M, Lip GY; Guideline Development Group, National Clinical Guideline for Management of Atrial Fibrillation in Primary and Secondary Care, National Institute for Health and Clinical Excellence. Stroke and thromboembolism in atrial fibrillation: a systematic review of stroke risk factors, risk stratification schema and cost effectiveness data. Thromb Haemost 2008;99:295-304.

28. Fuster V, Ryde'n LE, Cannom DS, et al. 2011 ACCF/AHA/HRS focused updates incorporated into the ACC/AHA/ESC 2006 Guidelines for the management of patients with atrial fibrillation: a report of the American College of Cardiology Foundation/ American Heart Association Task Force on Practice Guidelines developed in partnership with the European Society of Cardiology and in collaboration with the European Heart Rhythm Association and the Heart Rhythm Society. J Am Coll Cardiol 2011;57:e101-e198.

29. Palareti G, Cosmi B. Bleeding with anticoagulation therapywho is at risk, and how best to identify such patients. Thromb Haemost 2009;102:268-278.

30. Pisters R, Lane DA, Nieuwlaat R, et al. A novel user-friendly score (HAS-BLED) to assess 1-year risk of major bleeding in patients with atrial fibrillation: the Euro Heart Survey. Chest 2010;138:1093-1100.

31. Olesen JB, Lip GY, Hansen PR, et al. Bleeding risk in 'real world' patients with atrial fibrillation: comparison of two established bleeding prediction schemes in a nationwide cohort. J Thromb Haemost 2011;9:1460-467.

32. Cairns JA, Connolly S, McMurtry S, Stephenson M, Talajic M. CCS Atrial Fibrillation Guidelines Committee. Canadian Cardiovascular Society atrial fibrillation guidelines 2010: prevention of stroke and systemic thromboembolism in atrial fibrillation and flutter. Can J Cardiol 2011;27:74-90.

33. Keogh C, Wallace E, Dillon C, Dimitrov BD, Fahey T. Validation of the $\mathrm{CHADS}_{2}$ clinical prediction rule to predict ischaemic stroke. A systematic review and meta-analysis. Thromb Haemost 2011;106:528-538.

34. Karthikeyan G, Eikelboom JW. The $\mathrm{CHADS}_{2}$ score for stroke risk stratification in atrial fibrillation - friend or foe? Thromb Haemost 2010;104:45-48. 
35. Lip GY, Nieuwlaat R, Pisters R, Lane DA, Crijns HJ. Refining clinical risk stratification for predicting stroke and thromboembolism in atrial fibrillation using a novel risk factorbased approach: the Euro heart survey on atrial fibrillation. Chest 2010;137:263-272.

36. Van Staa TP, Setakis E, Di Tanna GL, et al. A comparison of risk stratification schemes for stroke in 79,884 atrial fibrillation patients in general practice. J Thromb Haemost 2011;9:39-48.

37. Olesen JB, Lip GY, Hansen ML, et al. Validation of risk stratification schemes for predicting stroke and thromboembolism in patients with atrial fibrillation: nationwide cohort study. BMJ 2011;342:124-28.

38. Boriani G, Botto GL, Padeletti L, et al. Improving stroke risk stratification using the $\mathrm{CHADS}_{2}$ and $\mathrm{CHA}_{2} \mathrm{DS}_{2}-\mathrm{VAS}_{\mathrm{c}}$ risk scores in patients with paroxysmal atrial fibrillation by continuous arrhythmia burden monitoring. Stroke 2011;42:1768-770.

39. CammAJ, Kirchhof P, Lip GY, et al. Guidelines for the management of atrial fibrillation: the Task Force for the Management of Atrial Fibrillation of the European Society of Cardiology. Europace 2010;12:1360-1420.

40. Olesen JB, Lip GY, Lindhardsen J, et al. Risks of thromboembolism and bleeding with thromboprophylaxis in patients with atrial fibrillation: a net clinical benefit analysis using a 'real world' nationwide cohort study. Thromb Haemost 2011;10:739-749.

41. Hart RG, Pearce LA, Aguilar MI. Meta-analysis: antithrombotic therapy to prevent stroke in patients who have non-valvular atrial fibrillation. Ann Intern Med 2007;146:857-867.

42. Davi G, Patrono C. Platelet activation and atherothrombosis. N Engl J Med 2007;357:2482-2494.

43. Cattaneo M. P2Y12 receptor antagonists: a rapidly expanding group of antiplatelet agents. Eur Heart J 2006;27:1010-12.

44. Van Walraven C, Hart RG, Connolly S, et al. Effect of age on stroke prevention therapy in patients with atrial fibrillation: the atrial fibrillation investigators. Stroke 2009;40:1410-416.

45. Lilienfeld DE, Chan E, Ehland J, etal. Mortality from pulmonary embolism in the United States: 1962 to 1984. Chest 1990;98: 1067-072.

46. Lilienfeld DE. Decreasing mortality from pulmonary embolism in the United States, 1979-1996. Int J Epidemiol 2000;29:465-69.

47. Kahn SR, Ginsberg JS. Relationship between deep venous thrombosis and the postthrombotic syndrome. Arch Intern Med 2004;164:17-26.

48. Ansell J, Hirsh J, Poller L, et al. The pharmacology and management of the vitamin K antagonists: The Seventh ACCP Conference on Antithrombotic and Thrombolytic Therapy. Chest 2004;126(3 Suppl):204S-233S.

49. Kearon C. Long-term management of patients after venous thromboembolism. Circulation 2004;110(Suppl 1):110-18.

50. Ahrens I, Lip GY, Peter K. New oral anticoagulant drugs in cardiovascular disease. Thromb Haemost 2010;104:49-60.
51. Watson HG, Greaves M. New anticoagulants: a story of promise and Disappointment. Br J Diabetes Vasc Dis 2007; 7:51-58.

52. Eriksson BI, Quinlan DJ, Weitz JI. Comparative pharmacodynamics and pharmacokinetics of oral direct thrombin and factor Xa inhibitors in development. Clin Pharmacokinet 2009; 48:1-2.

53. Dyke CK, Steinhubl SR, Kleiman NS, et al. First-in-human experience of an antidote-controlled anticoagulant using RNA aptamer technology: a phase 1a pharmacodynamic evaluation of a drug-antidote pair for the controlled regulation of factor IXa activity. Circulation 2006;114:2490-97.

54. Roehrig S, Straub A, Pohlmann J, et al. Discovery of the novel antithrombotic agent 5-chloro-N-(\{(5S)-2-oxo-3-[4-(3oxomorpholin-4-yl)phenyl]-1,3-oxazolidin-5-yl \} methyl) thiophene-2-carboxamide (BAY 59-7939): an oral, direct factor Xa inhibitor. J Med Chem 2005;48:5900-908.

55. Perzborn E, Strassburger J, Wilmen A, et al. In vitro and in vivo studies of the novel antithrombotic agent BAY 59-7939 - an oral, direct factor Xa inhibitor. J Thromb Haemost 2005;3: 514-521.

56. Kubitza D, Becka M, Wensing G, Voith B, Zuehisdorf M. Safety, pharmacodynamics, harmacokinetics of BAY 59-7939 - an oral, direct factor Xa inhibitor - after multiple dosing in healthy male subjects. Eur J Clin Pharmacol 2005;61:873-880.

57. Mueck W, Becka M, Kubitza D, Voith B, Zuehisdorf M. Population model of the pharmacokinetics and pharmacodynamics of rivaroxaban - an oral, direct factor Xa inhibitor - in healthy subjects. Int J Clin Pharmacol Ther 2007;45:335-344.

58. Matsushima N, Lee F, Sato T, Weiss D, Mendell J. Bioavailability and safety of the factor Xa inhibitor edoxaban and the effects of quinidine in healthy subjects. Clin Pharm Drug Dev 2013;2: 358-66.

59. Ogata K, Mendell-Harary J, Tachibana M, et al. Clinical safety, tolerability, pharmacokinetics, and pharmacodynamics of the novel factor Xa inhibitor edoxaban in healthy volunteers. J Clin Pharmacol 2010;50:743-53.

60. Conolly SJ, Ezekowitz MD, Yusuf S, et al, and the RE-LY Steering Committee and Investigators. Dabigatran versus Warfarin in Patients with Atrial Fibrillation. N Engl J Med 2009;361: 1139-151.

61. Gage BF (editorial). Can We Rely on RE-LY? N Engl J Med 2009;361:1200-01.

62. Connolly SJ, Eikelboom J, Joyner C, for the AVERROES Steering Committee and Investigators. Apixaban in Patients with Atrial Fibrillation. N Engl J Med 2011;364:806-817.

63. Patel MR, Mahaffey KW, Garg J, et al and the ROCKET AF Steering Committee, for the ROCKET AF Investigators. Rivaroxaban versus Warfarin in Nonvalvular Atrial Fibrillation. NEngl J Med 2011;365:883-891.

64. Granger CB, Alexander JH, McMurray JJV, for the ARISTOTLE Committees and Investigators. Apixaban versus Warfarin in Patients with Atrial Fibrillation. N Engl J Med 2011;365:981-992. 
65. Giugliano RP, RuffCT, Braunwald E, et al for the ENGAGE AFTIMI 48 Investigators. Edoxaban versus Warfarin in Patients with Atrial Fibrillation. N Engl J Med 2013;369:2093-104.

66. Schulman S, Kearon C, Kakkar AK, et al for the RE-COVER Study Group. Dabigatran versus Warfarin in the Treatment of Acute Venous Thromboembolism. N Engl J Med 2009;361: 2342-52.

67. The Hokusai-VTE Investigators. Edoxaban versus Warfarin for the Treatment of Symptomatic Venous Thromboembolism. N Engl J Med 2013;369:1406-15.

68. The EINSTEIN-PE Investigators. Oral Rivaroxaban for the Treatment of Symptomatic Pulmonary Embolism. N Engl J Med 2012;366:1287-297.

69. Van Ryn J, Stangier, J, Haertter S, et al. Dabigatran - a novel, reversible, oral direct thrombin inhibitor: interpretation of coagulation assays and reversal of anticoagulant activity. Thromb Haemost 2010;103:1116-127.

70. Satjit Bhusri and Jack Ansell. New anticoagulants in atrial fibrillation: an update for clinicians. Ther Adv Chronic Dis 2012;3(1):37-45.

71. Stratmann G, DeSilva A, Tseng E, et al. Reversal of direct thrombin inhibition after cardiopulmonary bypass in a patient with heparin induced thrombocytopenia. Anesth Analg 2004;98:1635-639.

72. Editorial. Apixaban and Rivaroxaban for stroke prevention in AF. DTB (Drugs \& Therapeutic Bulletin) 2014:52;6-9.

73. Douketis JD, Spyropoulos AC, Spencer FA, et al. Perioperative management of antithrombotic therapy: antithrombotic therapy and prevention of thrombosis, 9th ed: American College of Chest Physicians Evidence-Based Clinical Practice Guidelines. Chest 2012;141:2 Suppl:e326Se350S. [Erratum, Chest 2012;141:1129.]

74. Jacobs JM, Stessman J. New anticoagulant drugs among elderly patients is caution necessary?: comment on "the use of dabigatran in elderly patients". Arch Intern Med 171:1287-88.

75. Wasserlauf G, Grandi SM, Filion KB, Eisenberg MJ. Metaanalysis of rivaroxaban and bleeding risk. Am J Cardiol 2013;112(3):454-460.

76. Hull RD, Raskob GE, Pineo GF, et al. Subcutaneous lowmolecular-weight heparin vs warfarin for prophylaxis of deep vein thrombosis after hip or knee implantation. An economic perspective. Arch Intern Med 1997;157:298-303.

77. National Institute for Health and Care Excellence, 2013. Apixaban for preventing stroke and systemic embolism in people with nonvalvular atrial fibrillation (TA275) [online]. Available: http:/ /www.nice.org.uk/ta275 [Accessed 18 December 2013].
78. Harenberg J, Marx S, Diener HC, et al. Comparison of efficacy and safety of dabigatran, rivaroxaban and apixaban in patients with atrial fibrillation using network meta-analysis. Int Angiol 2012;31:330-39.

79. Testa L,Agnifili M, Latini RA, et al. Adjusted indirect comparison on new oral anticoagulants for stroke prevention in atrial fibrillation. Q J Med 2012;105:949-57.

80. Baker WL, Phung OJ. Systematic review and adjusted indirect comparison meta-analysis of oral anticoagulants in atrial fibrillation. Circ Cardiovasc Qual Outcomes 2012;5:711-19.

81. Adam SS, McDuffie JR, Ortel TL, Williams Jr. JW. Comparative effectiveness of warfarin and new oral anticoagulants for the management of atrial fibrillation and venous thromboembolism. A systematic review. Ann Intern Med 2012;157:796-807.

82. Bionid-Zoccai G, Malavasi V, D’Ascenzo F, et al. Comparative effectiveness of novel oral anticoagulants for atrial fibrillation: evidence from pair-wise and warfarin-controlled network metaanalyses. HSR Proc intensive Care Cardiovasc Anesth 2013; 5:40-54

83. Assiri A, Al-Majzoub O, Kanaan AO, et al. Mixed treatment comparison meta-analysis of aspirin, warfarin, and new anticoagulants for stroke prevention in patients with nonvalvular atrial fibrillation. Clin Ther 2013;35(7):967-84.

84. Miller CS, Grandi SM, Shimony A, et al. Meta-analysis of efficacy and safety of new oral anticoagulants (dabigatran, rivaroxaban, apixaban) versus warfarin in patients with atrial fibrillation. Am J Cardiol 2012;110:453-460.

85. Dogliotti A, Paolasso E, Giugliano RP. Novel oral anticoagulants in atrial fibrillation: a meta-analysis of large, randomised, controlled trials vs. warfarin. Clin Cardiol 2013;36:61-67.

86. Ruff CT, Giugliano RP, Braunwald E, et al. Comparison of the efficacy and safety of new oral anticoagulants with warfarin in patients with atrial fibrillation: a meta-analysis of randomised trials The Lancet, Early Online Publication, 4 December 2013 doi:10.1016/S0140-6736(13)62343-0: 15 March, 2014;383:955-962.

87. Larsen B, Lip GYH. Warfarin or novel oral anticoagulants for atrial fibrillation? The Lancet 2014;383:931-33.

88. Jackson T. Dabigatran and statins: faith, hype, and transparency. BMJ 2014;349:g4793.

89. Cohen D. Dabigatran: how the drug company withheld important analyses. BMJ 2014;349:4670.

90. Moore TJ, Cohen MR, Mattison DR. Dabigatran, bleeding, and the regulators. BMJ 2014;349:g4517.

91. Shafeeq $\mathrm{H}$ and Tran TH. New Oral Anticoagulants for Atrial Fibrillation. Are They Worth the Risk? P\&T 2014;39(1):54-64. 